\title{
Cathelicidin - A Novel Potential Marker of Pediatric Inflammatory Bowel Disease
}

This article was published in the following Dove Press journal:

Journal of Inflammation Research

\section{Paulina Krawiec \\ Elżbieta Pac-Kożuchowska}

Department of Pediatrics and

Gastroenterology, Medical University of Lublin, Lublin, Poland
Correspondence: Paulina Krawiec Department of Pediatrics and Gastroenterology, Medical University of Lublin, Racławickie I, Lublin 20-059.

Poland

Tel +48 8I 7185400

Fax +48 81 7431353

Email paulinakrawiec@umlub.pl
Introduction: Cathelicidin is a multifunctional host defense peptide which may also exert proinflammatory signals and contribute to the development of autoimmune disorders. We aimed to assess serum concentration of cathelicidin in children with inflammatory bowel disease (IBD) compared to healthy controls and to evaluate its relationship with disease activity and phenotype. Patients and Methods: The study group included 68 children with IBD. The control group comprised 20 children with functional abdominal pain. All patients and controls were tested for complete blood count, C-reactive protein, erythrocyte sedimentation rate and cathelicidin. Stool samples were collected to assess calprotectin.

Results: Cathelicidin was significantly increased in patients with ulcerative colitis (1073.39 $\pm 214.52 \mathrm{ng} / \mathrm{mL})$ and Crohn's disease $(1057.63 \pm 176.03 \mathrm{ng} / \mathrm{mL})$ patients compared to controls $(890.56 \pm 129.37 \mathrm{ng} / \mathrm{mL})(\mathrm{H}=16.28 ; p=0.0003)$. Cathelicidin was significantly elevated in children with active IBD $(1044.90 \pm 176.17 \mathrm{ng} / \mathrm{mL})$ and IBD remission $(1098.10 \pm 227.87$ $\mathrm{ng} / \mathrm{mL})$ compared to controls $(\mathrm{Z}=3.21 ; p=0.001 ; \mathrm{Z}=-4.12 ; p<0.0001$, respectively). Negative correlation between cathelicidin and calprotectin in children with ulcerative colitis was found $(\mathrm{R}=-0.39 ; p=0.02)$. Cathelicidin exhibited AUC of 0.815 for differentiation children with ulcerative colitis from the control group.

Conclusion: Serum cathelicidin is increased in children with Crohn's disease and ulcerative colitis regardless of clinical activity of the disease suggesting that it may be a potential biomarker of IBD. Inverse correlation between cathelicidin and fecal calprotectin may imply a disparate role of these molecules in the pathophysiology of pediatric ulcerative colitis.

Keywords: antibacterial peptides, Crohn's disease, LL-37, ulcerative colitis

\section{Plain Language Summary}

Antimicrobial peptides, including human cathelicidin, are small molecules acting as host defense peptides. Their altered expression and activity may play a role in the pathogenesis of some autoimmune diseases. However, data on its implications in the development of inflammatory bowel disease (IBD) are scarce. We found that serum levels of cathelicidin was significantly increased in children with ulcerative colitis and Crohn's disease regardless of disease activity and treatment status, suggesting that it may be a potential biomarker of IBD. Negative correlation between fecal cathelicidin and stool calprotectin in children with ulcerative colitis may imply their disparate role in the pathophysiology of pediatric ulcerative colitis.

\section{Introduction}

Inflammatory bowel disease (IBD) represents a spectrum of chronic immunemediated inflammatory disorders of the gastrointestinal tract including Crohn's disease and ulcerative colitis. ${ }^{1}$ Despite the growing incidence of IBD worldwide 
its pathogenesis remains intricate and incompletely understood. $^{1,2}$ A general model of IBD pathogenesis involves a complex interplay between host genetics, immune response, gut microbiota and environmental factors. ${ }^{1-3}$ It has been proposed that gene mutations and environmental factors play a role of triggers causing an impaired host immune response to gut microbiota which results in inflammation, dysfunction of epithelial barrier, and bacterial translocation. ${ }^{3}$ Alterations in gut microbiota in IBD may include qualitative and quantitative modifications of its composition and changes in microbial functional activity. ${ }^{3,4}$

Antimicrobial peptides (AMPs) are small molecules acting as host defense peptides (HDPs) of antimicrobial activity and immunomodulatory attributes which are widely distributed among various tissues. ${ }^{5}$ Although AMPs and HDPs may be used interchangeably, it appears that the term host defense peptides encompasses both the antimicrobial and immune-related functions. ${ }^{6,7}$

The host defense peptides exhibit activity against pathogenic microorganisms including bacteria, enveloped viruses and fungi ${ }^{6-8}$ Furthermore, HDPs act as modulators of the immune response. ${ }^{6-8}$ On the one hand these peptides display pro-inflammatory properties protecting the host against pathogens, while on the other hand anti-inflammatory activity suppresses enhanced inflammation. ${ }^{6-8}$ Anti-inflammatory activity of HDPs is associated with their modulation of cytokine-mediated responses, regulation of cell apoptosis and impact on the inflammatory cells. ${ }^{7,8}$ However, it appears that the function of HDPs in the regulation of immunity and inflammatory process is context-dependent. ${ }^{6}$ It is determined by HDPs' expression and concentration at the site of inflammation and their interplay with other elements of the innate and adaptive immune system. ${ }^{7}$

In the gastrointestinal tract HDPs protect the host against pathogens overgrowth and invasion, and on the other hand modulate the composition of the endogenous microbiota, contributing to the gut homeostasis. ${ }^{4,9}$ Thus, altered expression and impaired activity of HDPs may play an important role in IBD pathogenesis. ${ }^{2,4,10}$

HDPs comprise two major subfamilies including defensins and cathelicidins. ${ }^{5,11}$ The only known member of human cathelicidins is cathelicidin LL-37. ${ }^{8-10}$ Cathelicidin LL-37 is encoded as an inactive precursor by the CAMP gene which is located on the short arm of chromosome 3 (3p21.3). ${ }^{13,14}$ Pre-protein hCAP18 is cleaved extracellularly by proteinase- 3 to cathelicidin. ${ }^{13,15,16}$
Cathelicidin is a cationic and amphiphilic 37 amino acid peptide which assumes an analpha-helical structure. ${ }^{12,13}$ The peptide is constitutively expressed in neutrophil-specific granules, macrophages, monocytes, natural killer cells and multiple epithelial cells. ${ }^{13,17}$

Cathelicidin exhibits a wide range of antimicrobial activity and variety of immunomodulatory functions..$^{6-8,18,19}$ It provides a primary antimicrobial host defense against bacteria, viruses and fungi, acts as chemokine and promotes chemotaxis, stimulates phagocytosis, production of reactive oxygen species and immune mediators. ${ }^{6,8,18-20}$ Cathelicidin regulates cell death pathways by inducing apoptosis of epithelial cells and promoting neutrophils survival. ${ }^{19}$ It may also be involved in wound healing and angiogenesis. ${ }^{19}$ It appears that the microenvironment determines the pro- or anti-inflammatory effect of cathelicidin on cellular response. $^{18}$

Although cathelicidin is a multifunctional host defense peptide, it may also contribute to the development of autoimmune disorders. ${ }^{14,18,19}$ Recent research has revealed the role of cathelicidin in the pathophysiology of systemic lupus erythematosus, rheumatoid arthritis and psoriasis. ${ }^{14,21,22}$ However, data on its implications in the development of inflammatory bowel disease are scarce. ${ }^{23-26}$ To the best of our knowledge there is no study regarding cathelicidin in pediatric IBD. Thus, we aimed to assess serum concentration of human cathelicidin LL-37 in children with IBD compared to healthy controls. The second aim in the study group was to evaluate the relationship between cathelicidin and IBD clinical activity and phenotype, and inflammatory markers including C-reactive protein, erythrocyte sedimentation rate, white blood cell count and fecal calprotectin.

\section{Patients and Methods}

A cross-sectional study was conducted at the Department of Pediatrics and Gastroenterology, Medical University of Lublin, Poland from June 2017 to October 2019. In the study group we enrolled 68 consecutive children with IBD hospitalized at our department in the study period. Exclusion criteria from the study group were: lack of informed consent of parents and/or patient aged $\geq 16$ years old, any clinical or laboratory signs of acute infection at the time of enrolment, a history of a surgery within the 4 weeks prior to enrolment.

To determine IBD phenotype in patients we used the Paris Classification. ${ }^{27}$ We evaluated clinical activity of IBD using Pediatric Crohn's Disease Activity Index (PCDAI) and Pediatric Ulcerative Colitis Activity Index 
(PUCAI) in patients with Crohn's disease and ulcerative colitis, respectively. ${ }^{28,29}$ In patients with Crohn's disease remission was defined as $\leq 10$ points and active phase as $>10$ points according to the PCDAI in children with Crohn's disease. ${ }^{28}$ Remission of ulcerative colitis was defined as less than 10 points and the active phase as $\geq 10$ points according to the PUCAI. ${ }^{29}$

To the control group we recruited 20 children with functional abdominal pain recognized based on the Rome IV Diagnostic Criteria for Functional Gastrointestinal Disorders. ${ }^{30}$ Exclusion criteria from the control group included lack of informed consent of parents and/or patient aged $\geq 16$ years old, history of any organic disease, any clinical or laboratory signs of acute or chronic inflammation at the time of recruitment, and a history of a surgery within the 4 weeks prior the enrolment.

A peripheral blood sample was collected from all patients and controls for complete blood count, C-reactive protein $(\mathrm{CRP})$, erythrocyte sedimentation rate (ESR) and cathelicidin.

Venous blood was collected from the peripheral venous catheter following a period of overnight fasting. Whole venous blood was collected in EDTA-containing tubes for complete blood count and ESR analysis. Samples for CBC and ESR were analyzed directly after collection. The second blood sample was collected in a test tube without anticoagulant to obtain serum for CRP and cathelicidin analysis. After centrifugation, serum was divided into aliquots. The first one was used to assess CRP concentration directly after blood collection, while the other aliquots of serum were frozen at $-20^{\circ} \mathrm{C}$ until cathelicidin analysis.

Serum concentration of human cathelicidin antimicrobial peptide (CAMP) was measured using commercially available enzyme-linked immunosorbent assay (ELISA) kits according to the manufacturer's recommendations (Cloud-Clone Corp. Katy, TX, USA, Serial No.: 0BFB0A2EA3).

Stool sample was collected from patients with IBD to assess calprotectin level. Patients collected stool samples from the first stool in the morning into plain tubes. Stool samples were refrigerated at $2-8^{\circ} \mathrm{C}$ in the laboratory and analyzed within 72 hours after collection according to the test's procedure. Fecal calprotectin was evaluated using quantitative chemiluminescent sandwich immunoassay (CLIA). We used the automated LIAISON Calprotectin assay Ref. 318960 (DiaSorin Inc., Stillwater, MN 55082, USA). The test uses two monoclonal antibodies, the first one to capture calprotectin from the stool, ie, monoclonal antibody against calprotectin heterocomplex and the second one to detect calprotectin, ie, monoclonal antibody to S100A9 subunit.

For statistical analysis Statistica v. 13 software (StatSoft, Poland) was used. The data are presented as mean and standard deviation or median and range. We used appropriate non-parametric tests for analysis considering skewed distribution of variables and inhomogeneity of variance as indicated by W Shapiro-Wilk test and F-Fisher test, respectively. Comparisons between two groups were performed with the use of Mann-Whitney U-rank test. Differences between more than two means for more than two groups were tested by the $\mathrm{H}$ Kruskal-Wallis test. Analysis of correlations between parameters was performed with the Spearman's rank correlation coefficient. The results were considered statistically significant at $p<0.05$.

Receiver operating characteristic (ROC) analysis was used to establish the diagnostic utility of cathelicidin to detect IBD in children. The area under the receiver operating curve (AUC) with 95\% confidence intervals was determined. For cathelicidin we calculated sensitivity, specificity, accuracy, positive predictive value and negative predictive value for predicting IBD.

Written informed consent for participation in this study was obtained from a parent and also by a patient in case of a child aged $\geq 16$ years. The study was approved by the Bioethical Committee of Medical University of Lublin (KE-0254/289/2016).

\section{Results}

In the study group there were $43(63.2 \%)$ children with ulcerative colitis and 25 (36.8\%) with Crohn's disease. The mean age of patients with IBD was $13.6 \pm 3.1$ years old (median: 14.25 years; range: $6.5-18$ years old). The majority of patients exhibited features of clinically active disease $(39 ; 57.4 \%)$. Most of the children with IBD were on medications $(43 ; 63.2 \%)$, while $25(36.8 \%)$ of the patients were at IBD onset and treatment naïve. Table 1 summarizes the baseline clinical characteristics of the patients with IBD, as previously published. ${ }^{31}$

The control group comprised of 20 children (12 girls and 8 boys) with functional abdominal pain. The mean age of children was $11.9 \pm 3.47$ years old (median: 12.25 years; range: $4.5-17.5$ years). The detailed description of the study and control groups was published previously. ${ }^{31}$

In children with IBD, the serum level of cathelicidin $(1067.59 \pm 200.01 \mathrm{ng} / \mathrm{mL})$ was significantly increased 
Table I Demographic and Clinical Characteristics of Children with IBD

\begin{tabular}{|c|c|c|c|}
\hline & & $\begin{array}{l}\text { Ulcerative Colitis } \\
n=43(63.2 \%)\end{array}$ & $\begin{array}{l}\text { Crohn's Disease } \\
\mathrm{n}=25 \text { (36.8\%) }\end{array}$ \\
\hline Gender & $\begin{array}{l}\text { Boys } \\
\text { Girls }\end{array}$ & $\begin{array}{l}20(46.5 \%) \\
23(53.5 \%)\end{array}$ & $\begin{array}{l}13(52 \%) \\
12(48 \%)\end{array}$ \\
\hline \multicolumn{2}{|l|}{ Age (years) } & $\begin{array}{l}\text { Mean: } 13.6 \pm 3.4 \\
\text { Median: } 14.5 \\
\text { Range: } 6.5-18\end{array}$ & $\begin{array}{l}\text { Mean: } 13.7 \pm 2.6 \\
\text { Median: } 13.5 \\
\text { Range: } 8.5-18\end{array}$ \\
\hline Clinical activity of IBD & $\begin{array}{l}\text { Active } \\
\text { Remission }\end{array}$ & $\begin{array}{l}23(53.5 \%) \\
20(46.5 \%)\end{array}$ & $\begin{array}{l}16(64 \%) \\
9(36 \%)\end{array}$ \\
\hline \multirow[t]{2}{*}{ IBD disease activity indexes } & PCDAI & - & $\begin{array}{l}\text { Mean: } 28 \pm 21.9 \mathrm{pts} \\
\text { Median: } 30 \mathrm{pts} \\
\text { Range: } 0-65 \mathrm{pts}\end{array}$ \\
\hline & PUCAl & $\begin{array}{l}\text { Mean: } 24.6 \pm 22.9 \text { pts } \\
\text { Median: } 20 \text { pts } \\
\text { Range: } 0-75 \text { pts }\end{array}$ & - \\
\hline \multirow[t]{2}{*}{ IBD location according to Paris classification } & $\begin{array}{l}\mathrm{LI} \\
\mathrm{L} 2 \\
\mathrm{~L} 3 \\
\mathrm{~L} 3+\mathrm{L} 4 \mathrm{a}\end{array}$ & - & $\begin{array}{l}2(8 \%) \\
5(20 \%) \\
7(28 \%) \\
I I(44 \%)\end{array}$ \\
\hline & $\begin{array}{l}\text { EI } \\
\text { E2 } \\
\text { E3 } \\
\text { E4 }\end{array}$ & $\begin{array}{l}2(4.6 \%) \\
4(9.3 \%) \\
7(16.3 \%) \\
30(69.8 \%)\end{array}$ & - \\
\hline Treatment & $\begin{array}{l}\text { EEN } \\
5 A S A \\
\text { AZA } \\
5 A S A+A Z A \\
5 A S A+G C S \\
5 A S A+G C S+A Z A \\
\text { IFX } \\
\text { Treatment naïv }\end{array}$ & $\begin{array}{l}\text { N/A } \\
13(30.2 \%) \\
0(0 \%) \\
7(16.4 \%) \\
5(11.6 \%) \\
5(11.6 \%) \\
0 \\
13(30.2 \%)\end{array}$ & $\begin{array}{l}4(16 \%) \\
2(8 \%) \\
2(8 \%) \\
2(8 \%) \\
0(0 \%) \\
1(4 \%) \\
2(8 \%) \\
12(48 \%)\end{array}$ \\
\hline
\end{tabular}

Abbreviations: EEN, exclusive enteral nutrition; 5ASA, 5-aminosalicylate; AZA, azathioprine; GCS, glucocorticoids; IFX, infliximab.

compared to the control group $(890.56 \pm 129.37 \mathrm{ng} / \mathrm{mL})$, as presented in Figure 1.

The subgroup analysis, presented in Table 2, revealed that cathelicidin was significantly increased in patients with ulcerative colitis as well as patients with Crohn's disease compared to controls. However, there were no significant differences in cathelicidin concentration between patients with Crohn's disease and ulcerative colitis.

In the study group, concentration of cathelicidin was significantly increased in girls $(1125.90 \pm 212.64 \mathrm{ng} / \mathrm{mL}$; median: $1116.18 \mathrm{ng} / \mathrm{mL})$ compared to boys (1005.75 $\pm 167.49 \mathrm{ng} / \mathrm{mL}$; median: $1028.80 \mathrm{ng} / \mathrm{mL}) \quad(Z=2.41$; $p=0.02$ ). On the other hand, cathelicidin did not differ significantly between girls $(869.37 \pm 122.50 \mathrm{ng} / \mathrm{mL}$; median: $881.84 \mathrm{ng} / \mathrm{mL})$ and boys $(922.34 \pm 141.15 \mathrm{ng} / \mathrm{mL}$; median: $972.65 \mathrm{ng} / \mathrm{mL})$ in the control group $(Z=-1,11$; $p=0.26$ ).

We found that cathelicidin was significantly increased in children with active IBD (median: $1042.93 \mathrm{ng} / \mathrm{mL}$; range: $621.38-1473.33 \mathrm{ng} / \mathrm{mL}$; mean $\pm \mathrm{SD}$ : 1044.90 $\pm 176.17 \mathrm{ng} / \mathrm{mL})$ compared to healthy controls $(Z=3.21$; $p=0.001$ ). Moreover, cathelicidin was significantly elevated in children with IBD remission (median: 1112.68 $\mathrm{ng} / \mathrm{mL}$; range: $719.71-2028.39 \mathrm{ng} / \mathrm{mL}$; mean $\pm \mathrm{SD}$ : 1098.10 $\pm 227.87 \mathrm{ng} / \mathrm{mL})$ compared to the control group $(\mathrm{Z}=-4.12$; $p<0.0001)$. However, concentration of cathelicidin did not differ significantly between children in the active phase of 


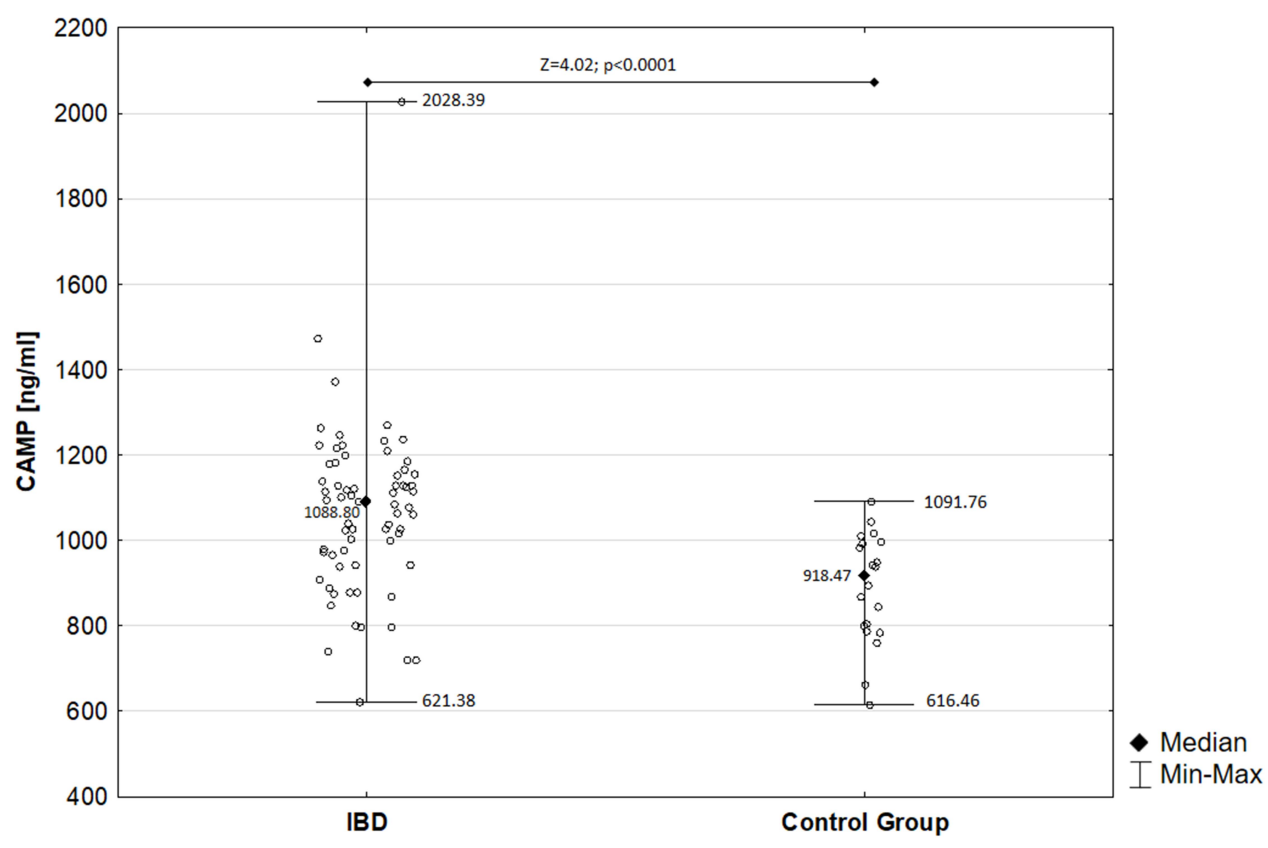

Figure I Comparison of serum cathelicidin in children with IBD and control group.

IBD and those in IBD remission $(\mathrm{Z}=-0.97 ; p=0.33)$. Detailed analysis is presented in Table 3.

Cathelicidin was significantly increased in children with IBD who were treatment naïve as well as those who received any treatment compared to controls. However, the concentration of cathelicidin did not differ significantly between treatment naïve patients with IBD compared to those who used any medications. Analysis of serum cathelicidin in children with IBD in terms of the treatment status compared to the control group is presented in Table 4.
Fecal calprotectin in children with IBD ranged from 18.2 to $8000 \mu \mathrm{g} / \mathrm{g}$, with median $1005 \mu \mathrm{g} / \mathrm{g}$ and mean \pm SD: 2043.46 $\pm 2311.88 \mu \mathrm{g} / \mathrm{g}$. There was no significant difference in fecal calprotectin between children with Crohn's disease (median: $1300 \mu \mathrm{g} / \mathrm{g}$; mean \pm SD: $2195.02 \pm 2265.93 \mu \mathrm{g} / \mathrm{g}$ ) and ulcerative colitis (median: $932.10 \mu \mathrm{g} / \mathrm{g}$; mean $\pm \mathrm{SD}$ : 1949.24 $\pm 2366.01 \mu \mathrm{g} / \mathrm{g})(p=0.59 ; \mathrm{Z}=0.54)$. Fecal calprotectin was significantly elevated in children with clinically active IBD (median: $2630 \mu \mathrm{g} / \mathrm{g}$; mean \pm SD: $2973.79 \pm 2290.66 \mu \mathrm{g} / \mathrm{g}$ ) compared to those in a clinical remission of IBD (median: $70 \mu \mathrm{g} / \mathrm{g}$; mean \pm SD: $315.69 \pm 987.55 \mu \mathrm{g} / \mathrm{g})(p<0.0001 ; \mathrm{Z}=5.76)$. There

Table 2 Comparison of Serum Cathelicidin in Children with Ulcerative Colitis, Crohn's Disease and Control Group

\begin{tabular}{|l|l|l|l|l|l|l|}
\hline Parameters & Groups & Mean & SD & Median & Range & Statistical Analysis \\
\hline Cathelicidin $[\mathrm{ng} / \mathrm{mL}]$ & Ulcerative colitis $(n=43)$ & 1073.39 & 214.52 & 1092.32 & $621.38-2028.39$ & $\mathrm{H}=16.28 ; p=0.0003^{* \wedge}$ \\
& Crohn's disease $(n=25)$ & 1057.63 & 176.03 & 1040.04 & $742.31-1473.33$ & \\
& Control group $(n=20)$ & 890.56 & 129.37 & 918.47 & $616.46-1091.76$ & \\
\hline
\end{tabular}

Notes: ${ }^{p} p<0.05$ when comparing ulcerative colitis and controls; ${ }^{\wedge} p<0.05$ when comparing Crohn's disease and controls.

Table 3 Comparison of Serum Concentration of Cathelicidin in Children with IBD in Terms of Disease Activity and Controls

\begin{tabular}{|l|l|l|l|l|l|l|}
\hline Parameters & Groups & Mean & SD & Median & Range & Statistical Analysis \\
\hline Cathelicidin $[\mathrm{ng} / \mathrm{mL}]$ & Active Crohn's disease $(\mathrm{n}=16)$ & 1054.54 & 188.41 & 1038.22 & $742.31-1473.33$ & $*$ * \\
& Inactive Crohn's disease $(\mathrm{n}=9)$ & 1063.12 & 162.33 & 1040.04 & $797.36-1272.40$ & \\
& Active ulcerative colitis $(\mathrm{n}=23)$ & 1038.20 & 171.15 & 1042.93 & $621.38-1372.95$ & \\
& Inactive ulcerative colitis $(\mathrm{n}=20)$ & 1113.85 & 254.13 & 1121.35 & $719.71-2028.39$ & \\
& Controls $(\mathrm{n}=20)$ & 890.56 & 129.37 & 918.47 & $616.46-1091.76$ & \\
\hline
\end{tabular}

Notes: *Z=2.43 $p=0.01$ when comparing active Crohn's disease to controls; ${ }^{\dagger} Z=-2.62 p=0.009$ when comparing inactive Crohn's disease to controls; ${ }^{\ddagger} Z=3.01$ l $p=0.002$ when comparing active ulcerative colitis to controls; ${ }^{*} Z=-3.96 p<0.0001$ when comparing inactive ulcerative colitis to controls. 
Table 4 Serum Cathelicidin in Children with IBD Depending on the Treatment Status Compared to the Control Group

\begin{tabular}{|l|l|l|l|l|l|l|}
\hline Parameters & Groups & Mean & SD & Median & Range & Statistical Analysis \\
\hline Cathelicidin[ng/mL] & Patients with IBD treatment naïve(n=25) & 1076.98 & 181.49 & 1095.50 & $742.31-1473.33$ & $\mathrm{H}=16.31 ; \mathrm{P}=0.0003^{* \wedge}$ \\
& Patients with IBD on any treatment $(\mathrm{n}=43)$ & 1062.13 & 211.93 & 1077.84 & $621.38-2028.39$ & \\
& Control group(n=20) & 890.56 & 129.37 & 918.47 & $616.46-1091.76$ & \\
\hline
\end{tabular}

Notes: ${ }^{*} p<0.05$ when comparing children with IBD treatment naïe and controls; ${ }^{\wedge}<<0.05$ when comparing children with IBD on medications and controls.

were positive correlations between fecal calprotectin and PCDAI $(\mathrm{R}=0.88, p<0.0001)$ and PUCAI $(\mathrm{R}=0.53 ; p<0.001)$.

Moreover, we found a significant negative correlation between serum cathelicidin and stool calprotectin in children with ulcerative colitis $(\mathrm{R}=-0.39 ; p=0.02)$, which is presented in Figure 2. However, there was no such correlation in patients with Crohn's disease.

There were no correlations between cathelicidin and IBD clinical activity indices, ie, PCDAI $(\mathrm{R}=-0.08$; $p=0.68)$ and PUCAI $(\mathrm{R}=-0.02 ; p=0.88)$ and laboratory markers of inflammation, ie, ESR ( $\mathrm{r}=0.04 ; p=0.74)$, CRP $(\mathrm{R}=0.06 ; p=0.62)$, and $\mathrm{WBC}(\mathrm{R}=0.12 ; p=0.46)$.

Subgroup analysis did not reveal any significant differences in cathelicidin among the study group depending on IBD location.

We evaluated the ability of cathelicidin to diverse children with IBD from the control group using receiver operating characteristic analysis. Analysis revealed a cut- off value of $1026.23 \mathrm{ng} / \mathrm{mL}$ for cathelicidin to discriminate patients with ulcerative colitis from controls, and a cut-off value of $1095.50 \mathrm{ng} / \mathrm{mL}$ for cathelicidin to discriminate patients with Crohn's disease from controls.

The areas under the receiver operating characteristic curves are plotted in Figures 3 and 4 for ulcerative colitis and Crohn's disease respectively. Table 5 presents measures of diagnostic accuracy of cathelicidin for the recognition of ulcerative colitis and Crohn's disease.

\section{Discussion}

Although recently there have been some research studies regarding novel biomarkers of IBD in children. ${ }^{32-34}$ to the best of our knowledge there has been no study analyzing cathelicidin in pediatric IBD. The molecular mechanism of cathelicidin's action and its regulatory pathways remain not fully understood. It has been presented that colonic subepithelial myofibroblasts are a major cellular source of

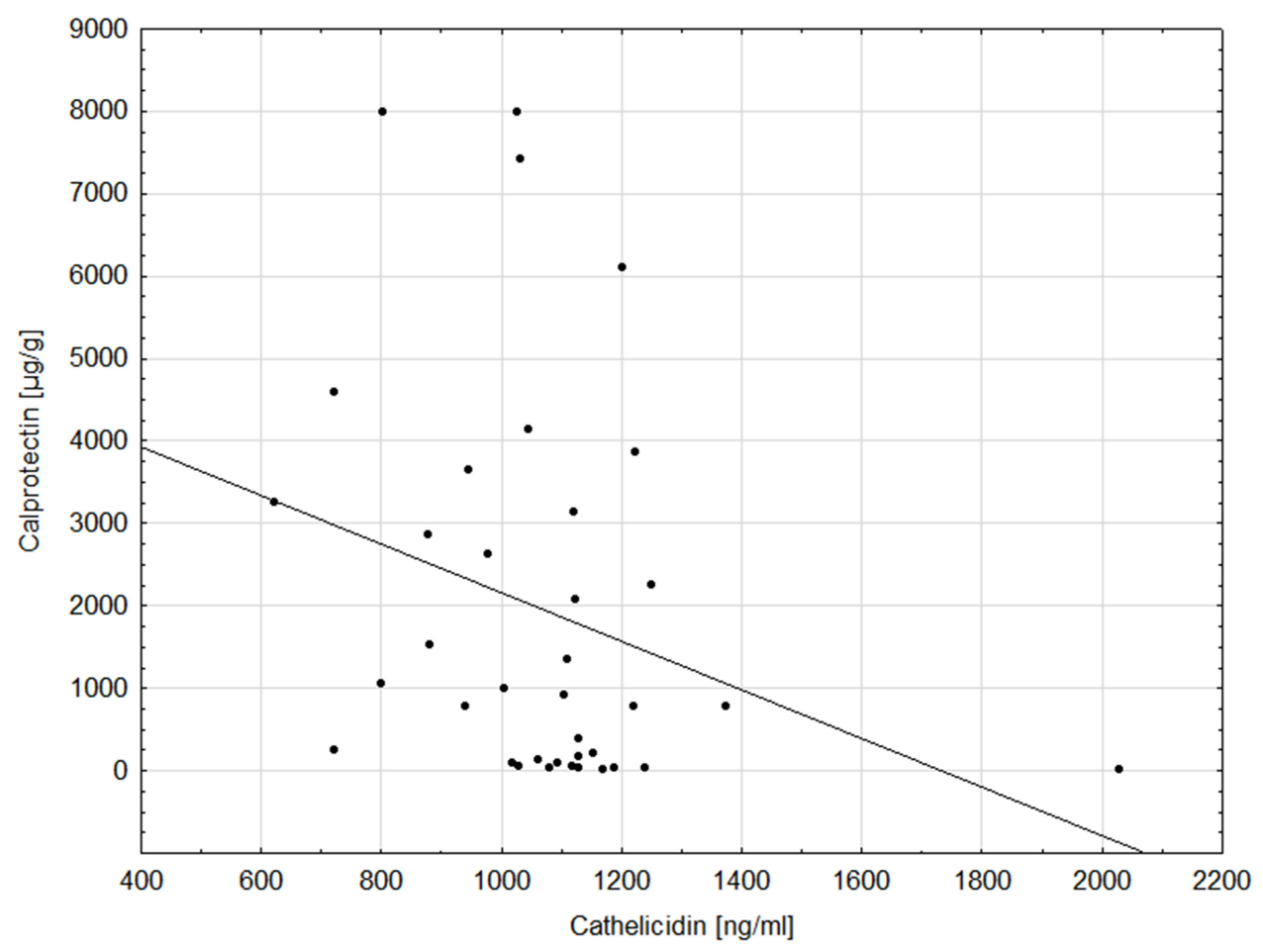

Figure 2 Relationship between serum cathelicidin and fecal calprotectin $(R=-0.39 ; p=0.02)$. 


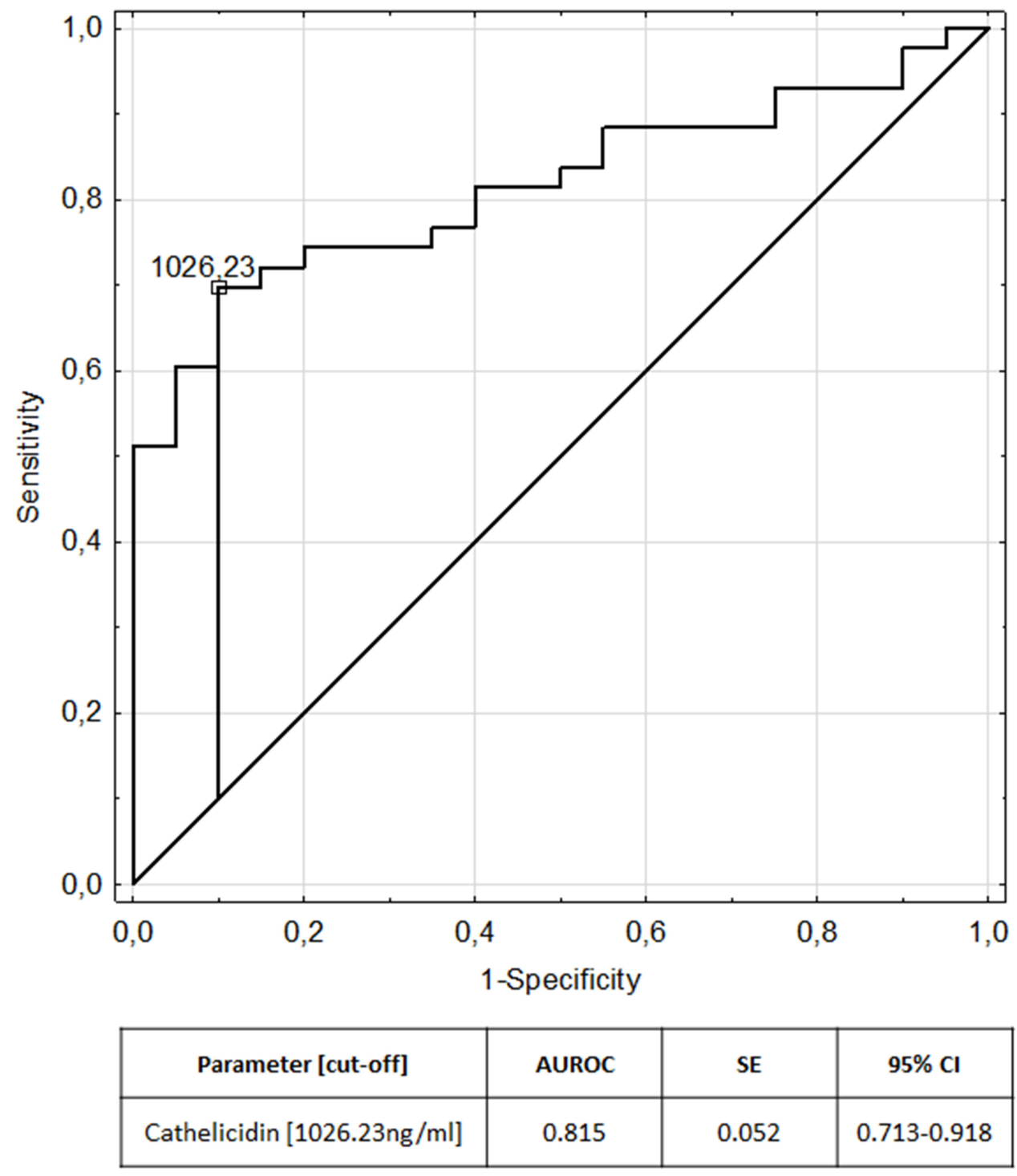

Figure 3 ROC curve and area under ROC for cathelicidin in recognition of ulcerative colitis.

cathelicidin in inflamed mucosa of IBD patients. ${ }^{25}$ Following stimulation by self-RNA released from necrotic cells, TLR3-mediated intracellular signaling pathway induces cathelicidin expression in colonic subepithelial myofibroblasts. ${ }^{14,25}$ Expression of cathelicidin is also activated by vitamin $\mathrm{D} 3$, endoplasmic reticulum stress, IFN $\gamma$, TNF $\alpha$, phenyl butyrate, and sodium butyrate. ${ }^{12}$

It has been found that 1.25-dihydroxyvitamin D3 induces expression of CAMP gene in humans and primates. ${ }^{35}$ However, the association between vitamin $\mathrm{D}$ and cathelicidin in IBD is not fully explored and captured. In a recent study, Gubatan et al presented a positive correlation between levels of $25(\mathrm{OH}) \mathrm{D}$ in serum and cathelicidin in serum and colon of patients with ulcerative colitis in clinical remission. ${ }^{36}$ Moreover, higher serum cathelicidin was associated with decreased histologic inflammation and risk of clinical relapse. ${ }^{36}$ Thus the results of Gubatan et al imply a beneficial role of increased serum cathelicidin levels in ulcerative colitis. ${ }^{36}$

It has been shown that the supplementation of vitamin $\mathrm{D}$ in adults with IBD may increase concentration of cathelicidin in plasma of patients with Crohn's disease ${ }^{37}$ and cathelicidin gene expression in whole blood of patients with ulcerative colitis. ${ }^{38}$ Moreover, Gubatan et al suggested that vitamin D treatment may induce production of endogenous cathelicidin in human colon cells. ${ }^{36}$ Thus, these findings may suggest a significant role of cathelicidin in mediating protective effects of vitamin D in patients with IBD. ${ }^{36}$

It appears that cathelicidin plays a dual role in inflammatory response. On the one hand cathelicidin may attenuate TLR 


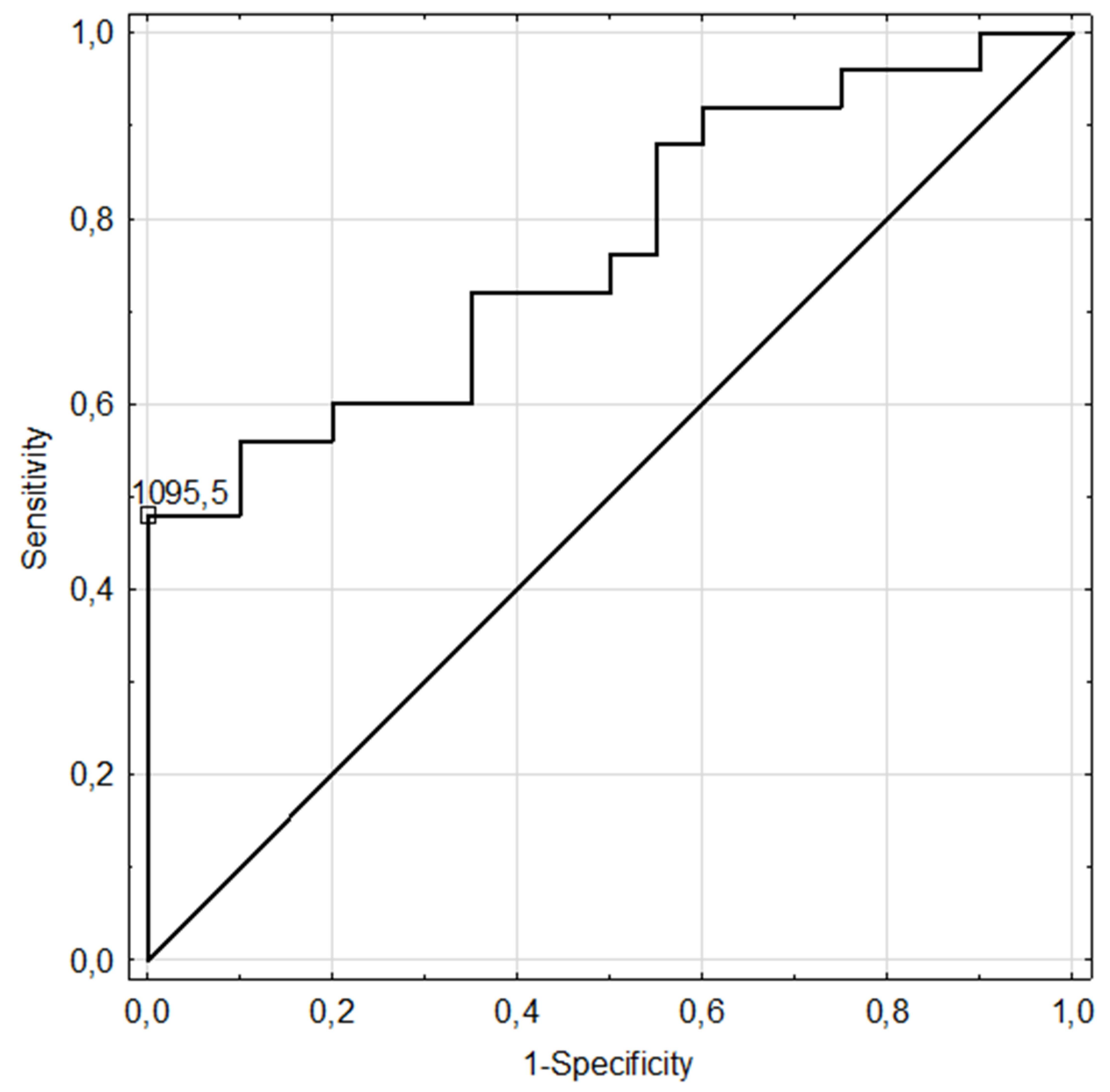

\begin{tabular}{|c|c|c|c|}
\hline Parameter [cut-off] & AUROC & SE & $95 \% \mathrm{Cl}$ \\
\hline Cathelicidin [1095.5ng/ml] & 0.766 & 0.07 & $0.629-0.903$ \\
\hline
\end{tabular}

Figure 4 ROC curve and area under ROC for cathelicidin in recognition of Crohn's disease.

signaling and bacterial-induced inflammation by binding to lipoteichoic acid or lipopolysaccharide, while on the other hand it exhibits pro-inflammatory activity by binding to nucleic acids and facilitating recognition of self-DNA by TLR9, self-RNA by TLR7 and TLR8, or double-stranded RNA by TLR $3 .{ }^{39}$ It has been suggested that, during infection, cathelicidin as an antimicrobial protein can exterminate microbes and promote recruitment and induction of inflammatory cells and at the same time protect the host from excessive immune response at the site of infection. ${ }^{39}$ Persistent expression of antimicrobial proteins may cause loss of tolerance to self-nucleic acids by the host, contributing to the development of autoimmune diseases. ${ }^{14,39}$ Defective expression or altered function of cathelicidin may also lead to dysbiosis and loss of tolerance to commensal microbiota which is considered as a critical element in the pathogenesis of IBD. ${ }^{12,39}$

Table 5 Measures of Diagnostic Accuracy of Cathelicidin in the Recognition of IBD

\begin{tabular}{|l|l|l|l|l|}
\hline Parameters [Cut-Off] & Sensitivity & Specificity & Accuracy & $\begin{array}{l}\text { Positive Predictive } \\
\text { Value }\end{array}$ \\
\hline Cathelicidin for recognition of ulcerative colitis $[1026.23 \mathrm{ng} / \mathrm{mL}]$ & 0.698 & 0.900 & 0.762 & 0.938 \\
Cathelicidin for recognition of Crohn's disease $[1095.5 \mathrm{ng} / \mathrm{mL}]$ & 0.480 & 0.950 & 0.689 & 0.923 \\
\hline
\end{tabular}


In our study we found that the serum level of cathelicidin was significantly increased in children with ulcerative colitis and Crohn's disease compared to the control group. Moreover, we presented that cathelicidin is elevated in both the active phase and the remission of IBD children regardless of treatment status compared to the control group. Receiver operating characteristic analysis revealed that serum cathelicidin may serve as a novel biomarker of pediatric IBD, particularly of ulcerative colitis. A further novel finding is that cathelicidin exhibited a negative correlation with fecal calprotectin in patients with ulcerative colitis.

Overall, our results are in accordance with findings reported by Tran et al who examined for the first time circulating levels of cathelicidin in adult patients with IBD. ${ }^{24}$ Their research revealed increased levels of serum cathelicidin in Crohn's disease and ulcerative colitis patients compared to healthy controls. ${ }^{24}$

In our study group, cathelicidin was significantly increased in patients in both the active and remissive phases of IBD compared to the control group. However, there were no significant differences in cathelicidin levels comparing children in IBD active phase and those in disease remission. Previous studies have reported inconsistent results regarding that issue. Kusaka et al showed that mRNA expression of cathelicidin was significantly up-regulated in inflamed mucosa of patients with ulcerative colitis as well as Crohn's disease compared to healthy mucosa. ${ }^{25}$ However, there were no differences between inactive mucosa of patients with IBD and normal mucosa of controls. ${ }^{25}$ It has been suggested that enhanced cathelicidin expression in the inflamed mucosa of IBD may improve antibacterial and anti-LPS activities, protecting tissues from microbial invasions and excess inflammatory response. $^{25}$ Thus, cathelicidin appeared to act as a protective agent against microbial invasion which could aggravate gut inflammation. ${ }^{25}$

On the other hand, Schauber et al presented that cathelicidin expression was increased only in patients with ulcerative colitis but not with Crohn's disease. ${ }^{23}$ It has been found that cathelicidin mRNA expression in both inflamed and non-inflamed colon mucosa of adults with ulcerative colitis was significantly increased compared to non-inflamed mucosa of healthy controls and to inflamed or non-inflamed colon mucosa from Crohn's disease adults. ${ }^{23}$ However, there were no significant differences in the expression of cathelicidin between inflamed or noninflamed mucosa from Crohn's disease patients and healthy mucosa. ${ }^{23}$ Schauber et al suggested that their results translate to various antimicrobial activity in IBD which may be diminished in Crohn's disease and enhanced in ulcerative colitis. ${ }^{23}$ The authors implied that defective induction of cathelicidin in Crohn's disease might result in a defective antimicrobial mucosal barrier providing bacterial adhesion and invasion which aggravated further inflammation. ${ }^{23}$

The reason for different observations between the current study and studies performed by Kusaka et al and Schauber et al may be complex. Firstly we evaluated the concentration of cathelicidin in sera of children with IBD, while in referenced studies the mRNA expression of cathelicidin was evaluated in colonic biopsies using real-time polymerase chain reaction. ${ }^{23,25}$ Moreover, we classified patients into active phase and remission of IBD based on clinical activity indices, not on histological scores of disease activity.

In adult patients with IBD it has been reportted that serum cathelicidin level is negatively correlated with Partial Mayo Score (PMS) and Harvey-Bradshaw Index which are indicators of clinical activity of ulcerative colitis clinical and Crohn's disease respectively. ${ }^{24}$ It implies that serum cathelicidin may indicate IBD activity. ${ }^{24}$ Moreover, Tran et al discovered that patients with moderate to severe IBD and high initial concentration of serum cathelicidin had significantly better recovery after 6-18 months compared to those with lower initial levels of cathelicidin. ${ }^{24}$ It may suggest that cathelicidin is a predictor of good clinical prognosis in adults with IBD. ${ }^{24}$

Although we did not find any relationship between cathelicidin and IBD clinical activity indices in our population of children with IBD, we showed a negative correlation between serum cathelicidin and fecal calprotectin in patients with ulcerative colitis. Calprotectin (S100A8/9) is a zinc- and calcium-binding cytosolic protein which is released from neutrophils upon their activation as a consequence of inflammation. ${ }^{40}$ Thus, the amount of calprotectin in feces reflects the flux of leukocytes into the intestinal lumen. ${ }^{41}$ Fecal calprotectin has been found as a highly sensitive and moderately specific marker of IBD in children. ${ }^{42,43}$ Elevated level of calprotectin has been also reported to predict relapse of IBD, ${ }^{40,44}$ while its low levels correlate with endoscopic mucosal healing in patients with IBD. $^{45}$

The inverse correlation between cathelicidin and calprotectin may imply disparate roles of these two molecules in the pathophysiology of pediatric ulcerative colitis. 
Animal models provide some insight in that finding. It has been revealed that cathelicidin poses potent anti-inflammatory effects against dextran sulfate sodium-induced colitis in mice and inhibits colitis-associated colonic fibrosis in trinitrobenzene sulphonic acid-induced chronic colitis. ${ }^{46-48}$ On the other hand Camp -/- mice developed a more severe form of DSS-induced colitis compared to wildtype mice. ${ }^{46}$ Thus targeting cathelicidin as a potential therapeutic agent in IBD appears to be a useful approach. $^{13}$

Calprotectin is a molecule included in endogenous damage-associated molecular patterns (DAMPs) proteins.49 Similarly to cathelicidin it may exert pro-inflammatory properties and antimicrobial function. ${ }^{49,50}$ The exact mechanism of the calprotectin's role in modulating the inflammatory response appears to be complex and is not fully understood. ${ }^{50}$ Calprotectin plays a role in the induction of autoreactive CD8+ T cells and the development of systemic autoimmunity. ${ }^{49}$ Moreover, calprotectin may lead to a dysfunction of epithelial barrier, which is considered to contribute in the development of IBD. ${ }^{49}$

The administration of neutralizing antibody against S100A9 suppressed dextran sulfate sodium (DSS)-induced colitis and azoxymethane (AOM)/DSS-induced colitisassociated colon cancer in murine model, providing a possible novel therapeutic approach in ulcerative colitis. ${ }^{51}$

The relationship between cathelicidin and calprotectin has been previously studied in various models. ${ }^{52-54}$ Smith et al found that although endotoxin exposure increases the concentration of cathelicidin in bronchoalveolar lavage fluid (BALf), it does not affect the concentration of calprotectin in BALf. ${ }^{52}$ That may result from the fact that cathelicidin is mainly expressed in the secretory granules of neutrophils and more easily mobilized than calprotectin which is a cytoplasmic protein. ${ }^{17,52}$ Hemshekhar et al reportted that the concentration of cathelicidin and calprotectin differs depending on the type of inflammatory disease. ${ }^{54}$ Both proteins were significantly elevated in the joint tissue of collagen-induced arthritic mice, while decreased in the lung tissues of HDM-induced allergic asthma mice. ${ }^{54}$ Bierkarre et al presented different expression of antimicrobial peptides in psoriasis and psoriatic arthritis suggesting heterogeneity in immune system dysfunction between these diseases. ${ }^{53}$ Thus, it appears that cathelicidin and calprotectin are differently altered and regulated depending on the local tissues involved in the inflammation and complex interactions between these molecules and other components of the immune system network. ${ }^{7,54}$

Furthermore we performed an analysis of the utility of serum cathelicidin in the diagnosis of IBD finding that it may be considered as a novel biomarker of pediatric IBD, particularly of ulcerative colitis. Cathelicidin exhibited AUC of 0.815 for differentiation of children with ulcerative colitis from the control group and AUC of 0.766 for differentiation of children with Crohn's disease from the control group.

Several limitations to this study need to be acknowledged, including relatively small and homogenic group of patients from a single center. Moreover, the control group is less numerous than the study group. However, it appears a challenging issue to enroll healthy children to the research study.

\section{Conclusion}

In conclusion, we have demonstrated that serum cathelicidin is increased in children with Crohn's disease and ulcerative colitis regardless of clinical activity of the disease and treatment status suggesting that it may be a potential biomarker of IBD. Inverse correlation between cathelicidin and fecal calprotectin in children with ulcerative colitis may imply their disparate role in the pathogenesis of pediatric ulcerative colitis. However, further studies are needed to fully elucidate the role of cathelicidin in IBD pathophysiology.

\section{Abbreviations}

AMPs, antimicrobial peptides; CRP, C-reactive protein; DAMPs, damage-associated molecular patterns; ESR, erythrocyte sedimentation rate; HDPs, host defense peptides; IBD, inflammatory bowel disease; PCDAI, Pediatric Crohn's Disease Activity Index; PUCAI, Pediatric Ulcerative Colitis Activity Index; ROC, receiver operating characteristic.

\section{Data Sharing Statement}

The datasets generated during and/or analyzed during the current study are available from the corresponding author on reasonable request.

\section{Ethics Approval and Informed Consent}

The study was approved by the Bioethical Committee of Medical University of Lublin (KE-0254/289/2016). 
Written informed consent for participation in this study was obtained from a parent and also by a patient in case of a child aged $\geq 16$ years. This study was conducted in accordance with the 1975 Declaration of Helsinki (6th revision, 2008).

\section{Author Contributions}

PK: conception and design of the study, data collection, analysis and interpretation, funding collection, drafting manuscript. EPK: conception and design of the study, data analysis and interpretation, critical revision of the manuscript for important intellectual content. All authors contributed to data analysis, drafting or revising the article, have agreed on the journal to which the article will be submitted, gave final approval of the version to be published, and agree to be accountable for all aspects of the work.

\section{Funding}

The study was funded by the Medical University of Lublin; Grant No. MNmb466 to PK.

\section{Disclosure}

The authors report no conflicts of interest in this work.

\section{References}

1. Sabino J, Verstockt B, Vermeire S, Ferrante M. New biologics and small molecules in inflammatory bowel disease: an update. Therap Adv Gastroenterol. 2019;12:1756284819853208. doi:10.1177/ 1756284819853208

2. Stange EF, Schroeder BO. Microbiota and mucosal defense in IBD: an update. Expert Rev Gastroenterol Hepatol. 2019;13(10):963-976. doi:10.1080/17474124.2019.1671822

3. Glassner KL, Abraham BP, Quigley EMM. The microbiome and inflammatory bowel disease. J Allergy Clin Immunol. 2020;145 (1):16-27. doi:10.1016/j.jaci.2019.11.003

4. Bevins CL. The immune system in IBD: antimicrobial peptides. In: Baumgart DC, editor. Crohn's Disease and Ulcerative Colitis. Springer, Cham; 2017:75-86.

5. Lei J, Sun L, Huang S, et al. The antimicrobial peptides and their potential clinical applications. Am J Transl Res. 2019;11(7):39193931.

6. van der Does AM, Hiemstra PS, Mookherjee N. Antimicrobial host defence peptides: immunomodulatory functions and translational prospects. Adv Exp Med Biol. 2019;1117:149-171. doi:10.1007/978-98113-3588-4_10

7. Prasad SV, Fiedoruk K, Daniluk T, Piktel E, Bucki R. Expression and function of host defense peptides at inflammation sites. Int $J$ Mol Sci. 2019;21(1):104. doi:10.3390/ijms21010104

8. Mookherjee N, Anderson MA, Haagsman HP, Davidson DJ. Antimicrobial host defence peptides: functions and clinical potential. Nat Rev Drug Discov. 2020;19(5):311-332. doi:10.1038/s41573-0190058-8
9. Ahluwalia A, Tarnawski AS. Cathelicidin gene therapy: a new therapeutic option in ulcerative colitis and beyond? Gene Ther. 2013;20 (2):119-120. doi:10.1038/gt.2012.23

10. Wehkamp J, Schmid M, Stange EF. Defensins and other antimicrobial peptides in inflammatory bowel disease. Curr Opin Gastroenterol. 2007;23(4):370-378. doi:10.1097/MOG.0b013e32 $8136 \mathrm{c} 580$

11. Mookherjee N, Brown KL, Hancock REW, Kastin AJ. Chapter 15 Cathelicidins. Handbook of Biologically Active Peptides (Second Edition). Academic Press; 2013:77-84.

12. Fabisiak A, Murawska N, Fichna J. LL-37: cathelicidin-related antimicrobial peptide with pleiotropic activity. Pharmacol Rep. 2016;68 (4):802-808. doi:10.1016/j.pharep.2016.03.015

13. Sun L, Wang W, Xiao W, Yang H. The roles of cathelicidin LL-37 in inflammatory bowel disease. Inflamm Bowel Dis. 2016;22(8):19861991. doi:10.1097/MIB.0000000000000804

14. Moreno-Angarita A, Aragón CC, Tobón GJ. Cathelicidin LL-37: a new important molecule in the pathophysiology of systemic lupus erythematosus. J Transl Autoimmun. 2020;3:100029. doi:10.1016/j. jtauto.2019.100029

15. Hooper LV, Alt FW. Chapter 3 - Epithelial Cell Contributions to Intestinal Immunity. Advances in Immunology. Academic Press; 2015:129-172.

16. Sørensen OE, Follin P, Johnsen AH, et al. Human cathelicidin, hCAP-18, is processed to the antimicrobial peptide LL-37 by extracellular cleavage with proteinase 3. Blood. 2001;97(12):3951-3959. doi:10.1182/blood.V97.12.3951

17. Scheenstra MR, van Harten RM, Veldhuizen EJA, Haagsman HP, Coorens M. Cathelicidins modulate TLR-activation and inflammation. Front Immunol. 2020;11:1137. doi:10.3389/fimmu.2020.01137

18. Kahlenberg JM, Kaplan MJ. Little peptide, big effects: the role of LL-37 in inflammation and autoimmune disease. $J$ Immunol. 2013;191(10):4895-4901. doi:10.4049/jimmunol.1302005

19. Nijnik A, Hancock RE. The roles of cathelicidin LL-37 in immune defences and novel clinical applications. Curr Opin Hematol. 2009;16(1):41-47. doi:10.1097/moh.0b013e32831ac517

20. Kim JM. Antimicrobial proteins in intestine and inflammatory bowel diseases. Intest Res. 2014;12(1):20-33. doi:10.5217/ir.2014.12.1.20

21. Dombrowski Y, Schauber J. Cathelicidin LL-37: a defense molecule with a potential role in psoriasis pathogenesis. Exp Dermatol. 2012;21(5):327-330. doi:10.1111/j.1600-0625.2012.01459.x

22. Neregård $P$, Engström $M$, Agerberth $B$, Catrina AI. LL-37 is expressed in the inflamed synovium in patients with rheumatoid arthritis and downregulated by TNF inhibitors. Ann Rheum Dis. 2012;71:A12. doi:10.1136/annrheumdis-2011-201230.26

23. Schauber J, Rieger D, Weiler F, et al. Heterogeneous expression of human cathelicidin hCAP18/LL-37 in inflammatory bowel diseases. Eur J Gastroenterol Hepatol. 2006;18(6):615-621. doi:10.1097/ 00042737-200606000-00007

24. Tran DH, Wang J, Ha C, et al. Circulating cathelicidin levels correlate with mucosal disease activity in ulcerative colitis, risk of intestinal stricture in Crohn's disease, and clinical prognosis in inflammatory bowel disease. BMC Gastroenterol. 2017;17(1):63. doi:10.1186/s12876-017-0619-4

25. Kusaka S, Nishida A, Takahashi K, et al. Expression of human cathelicidin peptide LL-37 in inflammatory bowel disease. Clin Exp Immunol. 2018;191(1):96-106. doi:10.1111/cei.13047

26. Hase K, Eckmann L, Leopard JD, Varki N, Kagnoff MF. Cell differentiation is a key determinant of cathelicidin LL-37/human cationic antimicrobial protein 18 expression by human colon epithelium. Infect Immun. 2002;70(2):953-963. doi:10.1128/iai.70.2.953963.2002

27. Levine A, Griffiths A, Markowitz J, et al. Pediatric modification of the Montreal classification for inflammatory bowel disease: the Paris classification. Inflamm Bowel Dis. 2011;17(6):1314-1321. doi:10.1002/ibd.21493 
28. Hyams JS, Ferry GD, Mandel FS, et al. Development and validation of a pediatric Crohn's disease activity index. J Pediatr Gastroenterol Nutr. 1991;12(4):439-447. doi:10.1097/00005176-199105000-00005

29. Turner D, Otley AR, Mack D, et al. Development, validation, and evaluation of a pediatric ulcerative colitis activity index: a prospective multicenter study. Gastroenterology. 2007;133(2):423-432. doi:10.1053/j.gastro.2007.05.029

30. Hyams JS, Di Lorenzo C, Saps M, Shulman RJ, Staiano A, van Tilburg M. Functional disorders: children and adolescents. Gastroenterology. 2016;150(6):1456-1468. doi:10.1053/j. gastro.2016.02.015

31. Krawiec P, Pac-Kożuchowska E. Serum interleukin 17A and interleukin $17 \mathrm{~F}$ in children with inflammatory bowel disease. Sci Rep. 2020;10(1):12617. doi:10.1038/s41598-020-69567-x

32. Vitali R, Stronati L, Negroni A, et al. Fecal HMGB1 is a novel marker of intestinal mucosal inflammation in pediatric inflammatory bowel disease. Am J Gastroenterol. 2011;106(11):2029-2040. doi:10.1038/ajg.2011.231

33. deZoeten EF, Battista KD, Colson SB, et al. Markers of hypoxia correlate with histologic and endoscopic severity of colitis in inflammatory bowel disease. Hypoxia (Auckl). 2020;8:1-12. doi:10.2147/ hp.s219049

34. Palmer NP, Silvester JA, Lee JJ, et al. Concordance between gene expression in peripheral whole blood and colonic tissue in children with inflammatory bowel disease. PLoS One. 2019;14(10):e0222952. doi:10.1371/journal.pone. 0222952

35. Gombart AF, Borregaard N, Koeffler HP. Human cathelicidin antimicrobial peptide (CAMP) gene is a direct target of the vitamin D receptor and is strongly up-regulated in myeloid cells by 1,25-dihydroxyvitamin D3. FASEB J. 2005;19(9):1067-1077. doi:10.1096/ fj.04-3284com

36. Gubatan J, Mehigan GA, Villegas F, et al. Cathelicidin mediates a protective role of vitamin D in ulcerative colitis and human colonic epithelial cells. Inflamm Bowel Dis. 2020;26(6):885-897. doi:10.1093/ibd/izz330

37. Raftery T, Martineau AR, Greiller CL, et al. Effects of vitamin D supplementation on intestinal permeability, cathelicidin and disease markers in Crohn's disease: results from a randomised double-blind placebo-controlled study. United European Gastroenterol J. 2015;3 (3):294-302. doi:10.1177/2050640615572176

38. Sharifi A, Hosseinzadeh-Attar MJ, Vahedi H, Nedjat S. A randomized controlled trial on the effect of vitamin D3 on inflammation and cathelicidin gene expression in ulcerative colitis patients. Saudi $J$ Gastroenterol. 2016;22(4):316-323. doi:10.4103/1319-3767.187606

39. Zhang L-J, Gallo RL. Antimicrobial peptides. Curr Biol. 2016;26(1): R14-R19. doi:10.1016/j.cub.2015.11.017

40. Foster AJ, Smyth M, Lakhani A, Jung B, Brant RF, Jacobson K. Consecutive fecal calprotectin measurements for predicting relapse in pediatric Crohn's disease patients. World J Gastroenterol. 2019;25 (10):1266-1277. doi:10.3748/wjg.v25.i10.1266

41. Banerjee A, Gupta RC. Chapter 15 - Gastrointestinal Toxicity Biomarkers. Biomarkers in Toxicology. Academic Press; 2014:269-277.

Journal of Inflammation Research

\section{Publish your work in this journal}

The Journal of Inflammation Research is an international, peerreviewed open-access journal that welcomes laboratory and clinical findings on the molecular basis, cell biology and pharmacology of inflammation including original research, reviews, symposium reports, hypothesis formation and commentaries on: acute/chronic inflammation; mediators of inflammation; cellular processes; molecular

Submit your manuscript here: https://www.dovepress.com/journal-of-inflammation-research-journal
42. Degraeuwe PL, Beld MP, Ashorn M, et al. Faecal calprotectin in suspected paediatric inflammatory bowel disease. $J$ Pediatr Gastroenterol Nutr. 2015;60(3):339-346. doi:10.1097/ MPG.0000000000000615

43. Daniluk U, Daniluk J, Krasnodebska M, Lotowska JM, SobaniecLotowska ME, Lebensztejn DM. The combination of fecal calprotectin with ESR, CRP and albumin discriminates more accurately children with Crohn's disease. Adv Med Sci. 2019;64(1):9-14. doi:10.1016/j.advms.2018.08.001

44. Costa F, Mumolo MG, Ceccarelli L, et al. Calprotectin is a stronger predictive marker of relapse in ulcerative colitis than in Crohn's disease. Gut. 2005;54(3):364-368. doi:10.1136/gut.2004.043406

45. Lee SH, Kim MJ, Chang K, et al. Fecal calprotectin predicts complete mucosal healing and better correlates with the ulcerative colitis endoscopic index of severity than with the Mayo endoscopic subscore in patients with ulcerative colitis. BMC Gastroenterol. 2017;17 (1):110. doi:10.1186/s12876-017-0669-7

46. Koon HW, Shih DQ, Chen J, et al. Cathelicidin signaling via the Tolllike receptor protects against colitis in mice. Gastroenterology. 2011;141(5):1852-63.e1-3. doi:10.1053/j.gastro.2011.06.079

47. Yoo JH, Ho S, Tran DH, et al. Anti-fibrogenic effects of the antimicrobial peptide cathelicidin in murine colitis-associated fibrosis. Cell Mol Gastroenterol Hepatol. 2015;1(1):55-74.e1. doi:10.1016/j. jemgh.2014.08.001

48. Tai EK, Wu WK, Wong HP, Lam EK, Yu L, Cho CH. A new role for cathelicidin in ulcerative colitis in mice. Exp Biol Med (Maywood). 2007;232(6):799-808.

49. Boyapati RK, Rossi AG, Satsangi J, Ho GT. Gut mucosal DAMPs in IBD: from mechanisms to therapeutic implications. Mucosal Immunol. 2016;9(3):567-582. doi:10.1038/mi.2016.14

50. Wang S, Song R, Wang Z, Jing Z, Wang S, Ma J. S100A8/A9 in inflammation. Front Immunol. 2018;9:1298. doi:10.3389/ fimmu.2018.01298

51. Zhang X, Wei L, Wang J, et al. Suppression colitis and colitisassociated colon cancer by anti-S100a9 antibody in mice. Front Immunol. 2017;8:1774. doi:10.3389/fimmu.2017.01774

52. Smith ME, Stockfelt M, Tengvall S, Bergman P, Lindén A, Qvarfordt I. Endotoxin exposure increases LL-37 - but not calprotectin - in healthy human airways. $J$ Innate Immun. 2017;9(5):475-482. doi: $10.1159 / 000475525$

53. Bierkarre H, Harder J, Cuthbert R, et al. Differential expression of antimicrobial peptides in psoriasis and psoriatic arthritis as a novel contributory mechanism for skin and joint disease heterogeneity. Scand J Rheumatol. 2016;45(3):188-196. doi:10.3109/ 03009742.2015.1091497

54. Hemshekhar M, Piyadasa H, Mostafa D, Chow LNY, Halayko AJ, Mookherjee N. Cathelicidin and calprotectin are disparately altered in murine models of inflammatory arthritis and airway inflammation. Front Immunol. 2020;11:1932. doi:10.3389/fimmu.2020.01932

mechanisms; pharmacology and novel anti-inflammatory drugs; clinical conditions involving inflammation. The manuscript management system is completely online and includes a very quick and fair peerreview system. Visit http://www.dovepress.com/testimonials.php to read real quotes from published authors. 